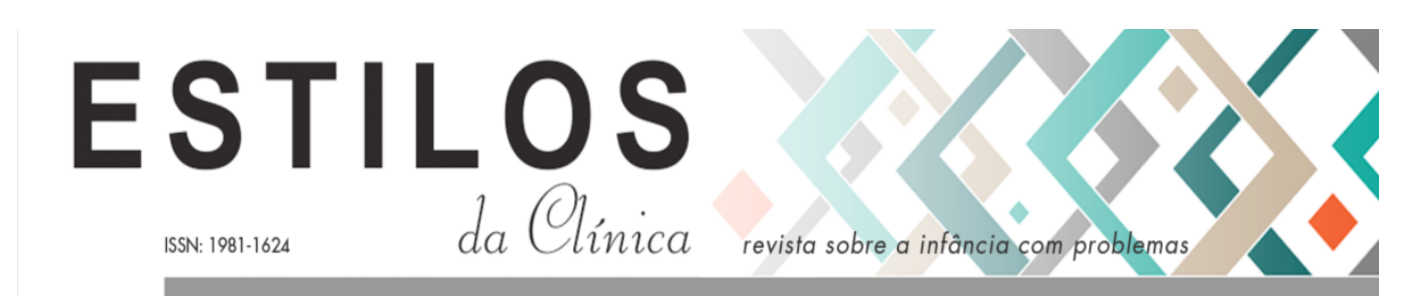

DOI: https://doi.org/10.11606/issn.1981-1624.v26i1p115-128.

\title{
Artigo
}

\section{Autismo: uma outra estrutura?}

\author{
Dayanna Pereira Santos
}

Resumo.O artigo propõe uma discussão acerca de um dos mais significativos debates teórico-clínicos no âmbito da psicanálise: o autismo é ou não uma psicose? Trata-se, ou não, de uma outra estrutura? No campo da teoria psicanalítica, observa-se a existência de premissas distintas que vão desde a ideia de uma semelhança/diferença estrutural entre autismo e psicose à conjetura do autismo como uma "não" estrutura. Tendo isso em vista, buscamos apresentar, neste artigo, as concepções de Lefort, R. e Lefort, de Vorcaro e de Jean-Claude Maleval sobre a estruturação psíquica dos autistas, as aproximações e distanciamentos em relação à clínica das psicoses. Com efeito, chegamos ao entendimento de que considerar o autismo como uma estrutura independente abre uma nova possibilidade de localização estrutural para o sujeito, o que implica reconhecer que há um modo singular de as crianças autistas se posicionarem frente à linguagem.

Palavras-chave: autismo; psicose; estrutura;linguagem;psicanálise.

\section{Autismo: ¿otra estructura?}

Resumen. El artículo propone una discusión sobre uno de los debates teórico-clínicos más significativos en el ámbito del psicoanálisis: ¿es el autismo una psicosis o no? ¿Es o no es otra estructura? En el campo de la teoría psicoanalítica, hay premisas distintas que van desde la idea de una similitud / diferencia estructural entre el autismo y la psicosis hasta la conjetura del autismo como una estructura del "no". Con esto en mente, buscamos presentar, en este artículo, las concepciones de Lefort, R. y Lefort, Vorcaro y Jean-Claude Maleval, sobre la estructuración psíquica de las personas autistas, las aproximaciones y distancias en relación a la clínica de las psicosis. De hecho, llegamos a entender que considerar el autismo como una estructura independiente abre una nueva posibilidad de ubicación estructural para el sujeto, lo que implica reconocer que existe una forma única para que los niños autistas se posicionen en relación al lenguaje.

Palabras clave:autismo; psicosis estructura; lenguaje; psicoanálisis.

* Pós-doutoranda em Psicologia pela Universidade Federal de Minas Gerais. Docente da

Universidade Federal de Goiás, Goiânia, GO, Brasil. E-mail: dayannagyn@hotmail.com 


\section{Autism: another structure?}

Abstract.The article proposes a discussion about one of the most significant theoretical-clinical debates in the scope of psychoanalysis: is autism a psychosis or not? Is it, or is it not, another structure? In the field of psychoanalytic theory, there are distinct premises that range from the idea of a structural similarity / difference between autism and psychosis to the conjecture of autism as a "no" structure. With this in mind, we seek to present, in this article, the conceptions of Lefort, R. and Lefort, Vorcaro and Jean-Claude Maleval, about the psychic structuring of autistic people, the approximations and distances in relation to the clinic of psychoses. In fact, we came to the understanding that considering autism as an independent structure opens up a new possibility of structural location for the subject, which implies recognizing that there is a unique way for autistic children to position themselves in relation to language.

Keywords:autism; psychosis; structure; language; psychoanalysis.

\section{L'autisme: une autre structure?}

Résumé. L'article propose une discussion sur l'un des débats théorico-cliniques les plus significatifs dans le cadre de la psychanalyse: l'autisme est-il une psychose ou non? Est-ce ou n'est-ce pas une autre structure? Dans le domaine de la théorie psychanalytique, il existe différentes prémisses qui vont de l'idée d'une similitude / différence structurelle entre l'autisme et la psychose à la conjecture de l'autisme en tant que structure «non». Dans cette optique, nous cherchons à présenter, dans cet article, les conceptions de Lefort, R. et Lefort, Vorcaro et JeanClaude Maleval, sur la structuration psychique des personnes autistes, les approximations et les distances par rapport à la clinique des psychoses . En fait, nous en sommes venus à comprendre que considérer l'autisme comme une structure indépendante ouvre une nouvelle possibilité de localisation structurelle pour le sujet, ce qui implique de reconnaître qu'il existe une manière unique pour les enfants autistes de se positionner par rapport au langage.

Mots clés: autisme; psychose; structure; Langue; psychanalyse.

Este artigo apresenta as concepções de Rosine e Robert Lefort, Vorcaro e de Jean-Claude Maleval sobre a estruturação psíquica dos autistas. Para tanto, situa a especificidade da estrutura autística em relação às psicoses, sublinhando elementos diagnósticos diferenciais e os desdobramentos da hipótese elaborada por Vorcaro acerca de que os casos de autismos, sobretudo na infância, revelam a possibilidade de diferentes amarrações entre o real, o simbólico e o imaginário, vinculadas a certa invenção e contingência de (in) possíveis formas de tratamento. Todavia, evidenciamos, no texto, não haver consenso quanto às abordagens sobre as diferenças entre o autismo e a psicose infantil, de modo que, quando a discussão envolve o tratamento dos autistas, emerge na literatura uma heterogeneidade de proposições sobre o assunto.

Nesse contexto, Porge (1998) enfatiza a função da invenção como artifício do processo analítico, adjunta à noção de transformação, a partir das marcas do sujeito, e a contrapõe à criação, que faz referência àquilo que se funda a partir do nada. Portanto, nossa interrogação recai sobre o "não decidido" da estrutura na infância, visto que

o ponto de vista da patologia não é o da estrutura. A patologia se inscreve numa ordem que fixa uma média estatística avaliável de normalidade (...). Dizer patologia já é conceber o tratamento como finalidade, um tratamento que visa a uma restitutio ad integrum. A patologia cria uma fronteira entre o cuidador e aquele que está sendo cuidado, situa-se do lado do doente, não do cuidador. A noção de estrutura desloca as fronteiras. Na estrutura não existe déficit, mas agenciamento de elementos de acordo com certas configurações, com certas relações que são variáveis. A estrutura não se refere a uma norma a priori, mas aos parâmetros do desejo e da demanda (Porge, 2014, p. 30; grifos do autor).

Interessa à psicanálise a dimensão enigmática dos autismos, entendendo-os em seu sentido estrutural e não conforme parâmetros de desenvolvimento, adotados por muitos da medicina psiquiátrica. Essa compreensão pode ser o "passo além dos outros" a que Lacan se referiu 
(1954-1955/1985) em relação à psicanálise. No que tange à estruturação subjetiva, não há de se conjugar fases evolutivas por não se conceber um a priori ou um a posteriori. A estruturação subjetiva ultrapassa a ideia de uma progressão contínua em que um movimento suplantaria o outro. Isso implica enfrentar as limitações de vocabulário e, de antemão, reconhecer a existência de um inconsciente em estruturação sob os efeitos da linguagem. Trata-se, portanto, de incluir, em um movimento de cotejamento, o inefável, as vacilações, o verbo forjado, naquilo que afeta o sujeito e "não cessa de não se escrever" (Lacan, 1982 [1972-73]). Nesse sentido, a dimensão enigmática dos autismos - cuja marca tem a ver com a insistência do funcionamento sinthomático - comparece como efeito do que se produz na trançagem RSI (Vorcaro, 2017).

Como uma escrita, a estruturação se faz em linhas tortuosas, descentradas, livres de sucessividade, nas quais se engendram diacronicamente os elementos fundantes do sujeito, que não é

sujeito no inconsciente, imaginado como um reservatório das pulsões, ele é a própria pulsação, é a fenda onde algo de não sabido - de inconsciente - se abre e se fecha assim que é apreendido pela consciência. O sujeito não é substancial, ele é o momento de eclipse que se manifesta no equívoco (Porge, 1996, p. 502).

Nesse sentido, a psicanálise distancia-se do discurso psicopatológico, centrado em normatizações, para, de um ponto de vista parcial, escutar algo de uma "estruturação do desejo em face à demanda, ao real, ao gozo" (Porge, 2014, p. 30). Este, por sua vez, é produzido no singular, via enodamento real, simbólico e imaginário. Sob esse prisma, qual seria o papel do analista na clínica com crianças/bebês? ${ }^{1}$ De que forma a sua posição incide no tratamento? Embora a clínica psicanalítica opere, especialmente, via fala, ela também se fundamenta na escuta que inclui a percepção de reações, desenhos, brincadeiras e outras manifestações. Nessa perspectiva, mesmo que a criança pequena ainda não tenha linguagem verbal, isso não equivale pensar que ela não possua uma linguagem, pois até a "forma de olhar é linguagem" (Dolto, 2002, p.114). Assim, ao contrário de uma relação dicotômica, encontra-se, nessa realidade, um corpolinguagem.

\section{A especificidade do autismo: a partir do trabalho clínico de Rosine e Robert Lefort}

Rosine e Robert Lefort, alunos de Lacan, a partir de suas observações sobre o autismo, a psicose e as neuroses severas, sustentam a tese de "estatuto do sujeito pela palavra" (Lefort, R. e Lefort, R., 1951-52/1984). A experiência clínica com crianças rendeu ao casal duas importantes obras, quais sejam: Nascimento do Outro (1951-52/1984) e A distinção do autismo (2017). Nessas obras, os autores consideraram a hipótese de que entre os impasses implicados no advento do falante localiza-se a ausência do Outro, o responsável por dar à criança "um corpo, com zonas erógenas prevalentes na vida pulsional" (Lefort, R. e Lefort, R.,1951$52 / 1984$, p. 42). Nesse sentido, para o casal de psicanalistas, o Outro nos autismos pressupõe uma ausência diferente, portanto, dos casos de psicose em que há Outro.

Todavia, a tese fundamental para Lacan é a de que o infans, desde antes de seu nascimento, já pertence a um mundo arquitetado pelo registro simbólico, logo, está inscrito no campo da

\footnotetext{
${ }^{1}$ Parafraseando Vorcaro $(1999,2004)$, a criança é o lugar onde se enlaçam: o organismo irredutível, presença inequívoca do real; a cadeia significante, que sustém a pré-existência do simbólico, a alternância inicial entre presença e ausência e o imaginário materno, que baliza as expectativas e antecipações empreendidas pelo Outro primordial da criança.
} 
linguagem. Em princípio, o neonato é pré-visto e pré-dito no e pelo Outro, pois ele não se constitui avulso. Com o funcionamento do significante, o primeiro efeito na criança é o que se pode depreender da distinção estabelecida entre os significantes da satisfação. Portanto, o próprio traço unário, marco um, decantado das distintas experiências vividas, é reencontrado na repetição. Há, pois, nesse caso, uma identificação pelo traço unário, sendo assumida sua alteridade radical que marca a intervenção intrusiva do Outro no corpo vivo e se repete em qualquer tentativa da criança para se representar. Por intermédio desse traço que situa a criança, os significantes que ela pode vir a apreender S1 e S2 abrangem e rasuram o traço unário.

Assim, a "rasura do corte do traço unário por um significante" incide na remissão de um significante a outro, isto é, "na repetição inaugural que visa ao gozo" (Vorcaro, 2017, p.12). Isso implica o fato de que a "identificação ao traço unário" provoca seu apagamento no vazio do qual originará o sujeito, articulando sua transferência pelo significante que, "num só tempo, o nega e o perpetua" (p.12). Esse significante só pode ser, segundo Lacan, "simbolizável pela inerência de um (-1) no conjunto dos significantes" (1960/1998, p. 833). Ele se encontra no lugar de "médium" de acesso à Coisa, das Ding, o objeto que jamais será reencontrado. Lacan entende a primeira perda do objeto da satisfação em uma perspectiva mítica. Para o autor, embora esse objeto nunca tenha sido perdido, tampouco nomeado, ele se resvala entre as palavras e as coisas. E assim, como não pode ser representado por outra coisa, o vazio o representa. Com isso, o psicanalista centrou a satisfação pulsional na ordem do real. Sem o significante (-1), os outros não representariam nada. Logo, o irrepresentável tem a função essencial de sustentar a própria cadeia significante. No processo de funcionamento dessa cadeia significante,

decanta-se o primeiro corte da linguagem que incide no organismo, nomeado por Lacan (1961-62, Inédito) como Traço Unário. Absolutamente despersonalizado de todo conteúdo subjetivo e de qualquer variação, esse traço implantado suportará toda a rede significante. Por isso, a necessidade estrutural do ideal-do-eu como ponto concreto de identificação inaugural do sujeito ao traço unário. Esse traço entalhado franqueia o surgimento de algo novo. Apagado de quase tudo que o distingue, esse um do traço distintivo só se distingue por ser, apenas, um traço. A identificação do sujeito se relacionará a esse núcleo real primeiro que, com a linguagem, corta o ser vivo (Vorcaro, 2017, p. 9 - grifo da autora).

Diante de tal conjetura, depreendemos que o infans, para sair da condição de puro organismo e se humanizar, aliena-se aos significantes vindos do Outro. $\mathrm{O}$ filhote humano vem ao mundo imerso num banho de linguagem, e tal imersão o determina. Existe, pois, um organismo submetido às contingências próprias do desenvolvimento as quais dão suporte imaginário ao falante. Esse suporte pode ou não advir. Isso vai depender das condições singulares de cada um ante o encontro com a linguagem. Nesse caso, o falante nascerá submetido não só à pulsão, mas também ao significante. Portanto, interrogar sobre as operações que compõem a origem do funcionamento psíquico do falante, partindo dos pressupostos freudianos e da releitura de Lacan, implica reconhecer que a captura da criança na e pela linguagem ocorre de distintas formas, como nos casos de autismos cuja principal característica é a dificuldade de estabelecer relações sociais e de comunicação.

Nesse sentido, a aposta na antecipação do sujeito não pode passar pelas certezas das palavras, mas pela ascendência de uma desconfiança frente a possíveis asserções. A esse respeito, lembramos também da escrita de Barthes, que, a nosso ver, sugere uma abertura à contradição, à latência e à inconclusão como procedimentos de constituição e de interpretação. Ora, a "palavra não é nem um instrumento, nem um veículo (...) disso decorre que ela nunca possa explicar o mundo, ou pelo menos, quando ela finge explicá-lo é somente para aumentar sua ambiguidade" (Barthes, 1970, p. 33). Logo, articulando as noções de das Ding e de desejo, 
depreendemos que o outro, agente materno, atua como instância pela qual se estabelece para o infans uma anterioridade fundadora, tornando possível o surgimento de uma estrutura temporal. Entendemos, pois, que uma abordagem possível dos autismos não pode prescindir de uma concepção do psíquico que comporte os efeitos da linguagem sobre o corpo. Os autismos colocam em relevo o que pode acontecer quando específicas contingências afetam a ação desse Outro.

A confluência da língua com o corpo engendra marcas no organismo que precisam ser decifradas para que se funde uma gramática concatenada com a rede do Outro e, nesse laço, cada sujeito traça trajetos singulares. O vivo é enquadrado pela lógica discursiva posta pelo simbólico, que lhe outorga um corpo. No caso dos autistas, não acontece de forma diferente, pois "a despeito de recusar o laço com os agentes do Outro, eles dão testemunho desse enquadramento até nos casos mais recrudescidos" (Meira, 2020, p.11, ). Todavia, apresentam um funcionamento psíquico que parece se dispor na linguagem de forma distinta do significante, provocando o surgimento de questões em relação aos usos particulares que fazem da linguagem e se esse uso tece uma estrutura clínica dessemelhante das categorias neurose, psicose e perversão.

A esse respeito, destacamos o trabalho clínico do casal Lefort com crianças em situações de risco psíquico. Isso porque a questão evocada pelos psicanalistas perpassa a hipótese de "não haver Outro" nos autismos e no valor da criação de soluções que permitam a cada autista se implantar no campo do Outro. Os Lefort compreenderam, a partir de referências clínicas engendradas pelo ensino de Lacan, o autismo fora dos modelos das estruturas clínicas postas pela psicanálise, diferenciando-a da psicose. Também problematizaram os efeitos da posição do analista em relação ao modo como o autista toma algo que lhe faz certa exterioridade.

Com efeito, diante da impossibilidade de ser representado por significantes, o autista não efetiva a operação de alienação, visto que "o significante não se torna corpo, não produz afeto" (Lefort, R. e Lefort, R., 1984 [1951-52], p. 84). A hipótese de fundar um laço corpo-a-corpo, sem divisão, leva os autores a pensar os autismos para além da via patológica, vinculando-os, a partir de Lacan, a uma trama argumentativa. Com essa proposição, os Lefort estabelecem uma diferenciação entre os autismos e as psicoses. Na visão dos psicanalistas, o psicótico possui tanto um objeto quanto um Outro, atrelados ao real como um objeto a mais. Conforme os autores,

na psicose, ainda que pudesse aí existir pulsão a partir do objeto real, o gozo é aquele
que do Outro a quem tudo é devido para salvaguardá-lo. No autismo, ainda o que
possa haver gozo, é de destruição que se trata; na ausência de qualquer objeto, resta
em jogo apenas a pulsão de morte, única pulsão fundamental que, sem a imagem
narcísica, exclui o amor, mas não o gozo. Na psicose, é o Outro que goza; no autismo,
é o sujeito, na língua e na cultura (Lefort, R. e Lefort, R., 1984 [1951-52], pp. 53-54).

O argumento sustentado pelos Lefort é o de que nos autismos emergem os efeitos causados pela não inscrição da falta e, portanto, pelo malograr da metáfora materna. Essa ausência posiciona o autista no lugar do objeto $a$ como não especularizável, sem imagem fundada no espelho do Outro, um puro real. Essa posição, todavia, não se con-figura como objeto do Outro, segundo o apresentado pela psicose. Nesse caso, o Outro total do autista não personifica uma falha que possa estabelecer alguma alteridade, fora-significante, locus privilegiado do objeto $a$. Para os autores, a não divisão do sujeito gera "a ausência correlativa de um resto, o (a)" (Lefort, 1984 [1951-52], p. 61). Impera, pois, nessa relação, a ameaça de uma dissolução da dimensão simbólica.

Diante da impossibilidade de ser representado por significantes, o autista não efetiva a operação de alienação, visto que "o significante não se torna corpo, não produz afeto" (Lefort, 
R. e Lefort, R., 1984 [1951-52], p. 84). A hipótese de fundar um laço corpo-a-corpo, sem divisão, leva os autores a pensar os autismos para além da via patológica, vinculando-os, a partir de Lacan, a uma trama argumentativa. Com essa proposição, os Lefort estabelecem uma diferenciação entre os autismos e as psicoses. Na visão dos psicanalistas, o psicótico possui tanto um objeto quanto um Outro, atrelados ao real como um objeto a mais. Conforme os autores,

\begin{abstract}
na psicose, ainda que pudesse aí existir pulsão a partir do objeto real, o gozo é aquele que do Outro a quem tudo é devido para salvaguardá-lo. No autismo, ainda o que possa haver gozo, é de destruição que se trata; na ausência de qualquer objeto, resta em jogo apenas a pulsão de morte, única pulsão fundamental que, sem a imagem narcísica, exclui o amor, mas não o gozo. Na psicose, é o Outro que goza; no autismo, é o sujeito, na língua e na cultura (Lefort, R e Lefort, R., 1984 [1951-52], pp. 53-54).
\end{abstract}

O argumento sustentado pelos Lefort é o de que nos autismos emergem os efeitos causados pela não inscrição da falta e, portanto, pelo malograr da metáfora materna. Lacan (1974/1981, p. 17) esclarece que o objeto $a$ faz a separação entre o gozo do corpo, lido como gozo da vida, e o gozo fálico. Sob esse prisma, o trabalho na clínica psicanalítica com autistas considera os duplos e os objetos autísticos elementos singulares e passíveis de serem adotados na formulação de uma borda entre os registros Real, Simbólico e Imaginário. Nesse sentido, ao invés de tomar a manifestação do autista de forma isolada conforme signos herméticos sem concatenação, pressupomos que seus atos admitem uma invenção singular para lidar com o que lhe faz alteridade, constituindo uma borda autística que comporta uma lógica subjetiva que exige reconhecimento e franqueamento do analista, ao tomá-la como um escrito a ser lido, decifrado.

\title{
O enigma da estruturação subjetiva no autismo e o nó borromeano: sob a ótica de Vorcaro
}

Lacan (1974-75) apresenta o esquema do nó borromeano como objeto topológico, ${ }^{2}$ amarração de três registros: o imaginário, algo da ordem do sentido unívoco a partir das semelhanças e dessemelhanças; o simbólico, da ordem do equívoco organizado a partir do furo duplo sentido, valor "binário" do significante, e o real, o impossível de ser representado, tomado como o inverso do imaginário, portanto, o não-sentido ou não-senso. A amarração entre os registros se realiza pela consistência de cada um.

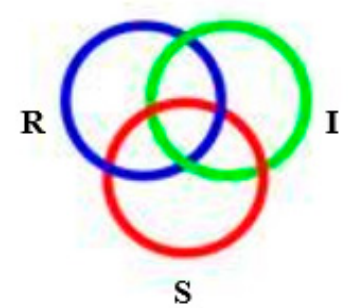

Figura 1. Nó borromeano de três elos (Lacan, 1974/75)

${ }^{2}$ Cf. Granon-Lafont. (1988). A topologia de Jacques Lacan. Jorge Zahar: Rio de Janeiro. 
Cada aro da imagem cruza-se em dois pontos e possui uma posição simétrica em relação aos demais. Por exemplo, o aro R passa duas vezes por baixo do aro I e duas vezes por cima do aro S. Já o aro S passa duas vezes sobre o aro I e duas vezes sob o aro $\mathrm{R}$, e assim sucessivamente. Há uma singularidade nesse enlaçamento e isso acontece porque cada aro só se prende a outro se estiver enlaçado por um. Na incidência de desatar qualquer um desses elos, o nó, em sua amplitude, será desfeito _um fato de consistência. Do ponto de vista analítico, é possível considerar que a consistência do nó é o que permite ao falante suportar as vicissitudes de sua existência ao longo da vida, pois "não há consistência que não se suporte no nó. É nisto que, do nó, a própria ideia do Real se impõe" (Lacan, 1974-75, aula de 15/04/75). O que está em jogo é o alcance de um efeito de ponto instituído por três retas sólidas, compostas pelas aberturas dos aros que formam o nó.

Vorcaro (2004), a partir de Lacan, considera o nó de três elos como uma estrutura mínima. Isso porque, ao ser cortado um dos elos, não importa qual deles, todos imediatamente se soltam e o nó se desfaz. De acordo com Lacan, "essa propriedade sozinha homogeneíza tudo o que há de número a partir de três (...). É sempre de três que ele [o nó] trará a marca" (Lacan, 19741975, p. 6). Consideramos que o nó borromeano RSI de três elos é imprescindível para a constituição do sujeito a devir e para o entendimento de que suas falhas apenas serão diferenciadas depois que ele reparar seus lapsos com o quarto elo - o sinthoma. O impasse subjetivo pode ser compreendido como o ponto em que o sujeito em constituição se arrisca a enodar-se, a amarrar-se em termos sinthomáticos. Desse modo, na infância, a estrutura psíquica não é decidida, isto é, "o não decidido da criança implica a impossibilidade de fazer equivaler a estruturação de uma criança à estruturação do adulto. Assim, a incidência de nossa fala pode mudar o modo de gestão do gozo dessas crianças" (Vorcaro, 2005, p. 41). Há, pois, uma não ligação definitiva entre significante e o ato.

A partir dessa não equivalência da estruturação de uma criança à de um adulto, Vorcaro qualifica o tempo de constituição psíquica como um trabalho imaginário e simbólico sobre o corte real, tendo em vista a tônica da descontinuidade entre RSI. Esse processo configura-se por uma variação na estruturação do sujeito a devir, coesa com as enunciações de uma estrutura não determinada na infância, e pela indagação sobre a inflexibilidade na sincronia (autônoma) da estrutura. Assim, a condição estrutural da criança é a de um decurso de estruturação que concebe um sujeito em constituição. A respeito dessa relação que se estabelece entre estrutura e temporalidade, Vorcaro (2005) faz a seguinte consideração:

\footnotetext{
Situar a criança na estruturação subjetiva exige a hipótese de que não há insuficiência de linguagem em nenhuma criança, a despeito dos modos como ela se apresenta. Há condições de circulação significante na trajetória lógica de sua estruturação e no aprisionamento a impasses que podem ser gerados nessa trajetória. Abordar a realidade psíquica da criança implicará o recolhimento do tecido significante articulado pelos sentidos, localizando neles marcas que balizam sua constituição para reconhecer as senhas que poderão operar sua leitura (Vorcaro, 2005, p.13).
}

Em relação à condição dos autismos, a autora salienta ser possível constatar que os incidentes engendrados nos cruzamentos entre Real, Simbólico e Imaginário são eventos constitutivos da estrutura tridimensional da realidade psíquica de um sujeito qualquer. No entanto, são seus contrassensos que permitem realçar "os desastres que a série psicopatológica grave diferenciada da psicanálise localiza nas manifestações infantis qualificadas como autismo, psicose, fenômenos psicossomáticos e debilidade mental" (Vorcaro, 2008, p.15). Diante do exposto, a hipótese levantada é a de que esses acontecimentos emergem como modos distintos de a criança fazer-se sujeito na e pela linguagem. Seria, pois, a forma como se dá o desatamento do nó e sua reparação. 
Desse modo, a solução que cada sujeito pode dar para seu lapso faz a diferença, por exemplo, entre a neurose e a psicose. Essa reparação constitui a escrita inventiva do nó de cada falante. Nesse processo, o inconsciente insurge de forma pulsátil e fugaz como tropeço, como equívoco na palavra de cada um. Ele se faz passar por um lapso e revela sua dimensão real de pura exsistência na fala. Com essa operação, depreendemos que o inconsciente não comunga da mesma língua da Linguística, embora estruturado e funcionando como a linguagem que admite esse elemento distintivo. Importa salientar que as modificações e as subversões engendradas por Lacan em relação à estrutura da linguagem não incidem em progressos ou retrocessos, mas antes em complexificações que retornam umas sobre as outras no curso da obra, tornando mais sofisticada a teoria lacaniana.

Imergimos nessa discussão a fim de refletir sobre as seguintes questões: É possível a criança autista estar na linguagem mesmo sem a função da fala? O que faz a fala da criança autista diferente das outras crianças? Para as crianças em vias de autismo, a linguagem e suas manifestações como a fala têm ou não função simbólica e imaginária? Em caso afirmativo, a estrutura da língua possui ou não a função constitutiva? Seria possível afirmar que os distúrbios da linguagem tangenciam o rastro de um sujeito na singularidade de sua inscrição no laço discursivo? Segundo Leite (2005), a possibilidade de delinear possíveis respostas para essas questões passa pela "dependência de podermos construir uma inteligibilidade quanto aos processos que presidem a articulação do real do organismo com o lugar simbólico que preexiste ao sujeito, articulação esta sustentada pela via do imaginário materno" (Leite, 2005, p. 291). O primordial nessa busca é que a lógica do simbólico permite estear uma não determinação estrutural na infância e, no que alude ao psicopatológico, uma possível exclusão na condição do autismo.

Nesses termos, o autismo como a recusa mais radical à alteridade evidencia, via nó borromeano, a operação em que o Imaginário encontra-se destrelado dos dois outros registros: o Real e o Simbólico, devido a um erro no nó que "impede a realidade psíquica". Com isso, supõe-se

a impossibilidade presente de enodar o real da linguagem que se imiscuiu fazendo traço no corpo (por meio do qual o infans ressoa lalíngua), com o registro do imaginário que iria representá-lo (por meio do estabelecimento de comparações, similitudes ou dessemelhanças, transpondo-as para o registro discretizado da língua) (Vorcaro, 2016, pp. 749-750).

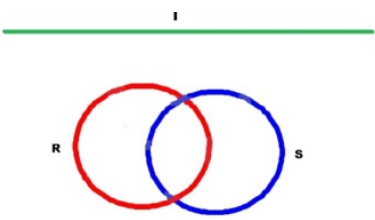

Para tratar tal estrutura, faz-se necessário destacar que o registro imaginário é o suporte do sentido. Portanto, em casos de autismos, o seu não enlaçamento com o simbólico e o real incidirá em efeitos justamente na composição da imagem corporal e na passagem da operação de alienação à separação. Isso não indica que ele deixou de operar ou de produzir efeitos, pois situa o ponto cuja delimitação central define o lugar do objeto $a$. Logo, lalangue estabelece uma relação de continuidade entre sentido e sem-sentido, ao se articular tanto ao sentido originário da experiência de satisfação quanto ao sem-sentido, prévio a qualquer posição de simbolização.

Nessa perspectiva, os lapsos implicados nos entrecruzamentos entre Real, Simbólico e Imaginário, que incidem sobre o nó borromeano, "não apenas enquanto contingência temporal como também enquanto formação do inconsciente" são acontecimentos constitutivos da 
estrutura tridimensional da realidade psíquica de um sujeito qualquer (Vorcaro, 2004, p.129). Assim, determinadas contingências que afetam o modo de reparar os lapsos podem incidir como um desastre na constituição subjetiva do infans, provocando efeitos diversos, entre eles o autismo. Com isso, urge a operação de um quarto elo capaz de manter atados os três registros, ou seja, de operar no ponto de recobrimento em que ocorre o impasse dos registros. Para Vorcaro (2004), a possibilidade de instauração de um quarto elo, na função de suplência, pode causar nova organização na estrutura e também constituir-se como uma aposta para o tratamento dos casos de autismo. Logo, o modo como se dá o desatamento e o reatamento do nó pode caracterizar a estruturação subjetiva do sujeito.

\section{Autismo e primado do signo: na leitura de Jean-Claude Maleval}

Na concepção de Maleval (2015), nos autismos, diferentemente da psicose, há o primado do signo, expresso tanto pela recusa parcial da função da fala quanto pela verbosidade ou até mesmo pelo uso de holófrases nos casos de autismos. Para o autor, o primado do signo, nos autismos, refere-se a uma espécie de degradação do significante (Maleval, 2015), pois seu uso é apagado em relação ao signo, não havendo, portanto, uma separação completa do referente. Desse modo, o emprego do signo é captável pelo fato de a criança autista, em seu escopo de fala, fixar-se na referência da coisa representada (Vorcaro, 2015). Isso explica a tendência do autista em adotar ícones como artifício para a comunicação. Ele está na linguagem e assujeitase a ela, mesmo que fora do discurso. Assim, as aparições holofrásicas são evidenciadas, mesmo não sendo possível localizar seus furos.

No autismo há foraclusão do objeto em razão de o olhar materno elidir a criança do desejo, incidindo no embaraço da factível relação do infans com o Outro (Jerusalinsk, 1993). Nessa circunstância, a criança autista não é tomada pelo significante, "não acolhe demandas nem apela para anular o Outro" (Soler, 1999, p.229). Logo, a relação do infans com o Outro é impossibilitada pelo não engendramento dos significantes que fazem do mundo uma rede de traços cuja abertura de um tempo a outro se torna possível. Em função disso, a realidade externa não assume a organização de um campo passível de ser compartilhado socialmente. Subtraemse do corpo as palavras e a condição de laço social. Dito de outro modo, com o rechaço da enunciação impede-se que o gozo embarque na palavra. Há, nessa operação, um anteparo à possibilidade de a língua se corporificar. Distinto do universo do sujeito falante, "cuja característica essencial é que nele é possível se enganar" (Lacan, 1962-63/2005, p. 87), o autista não se deixa enganar.

Tendo em vista os pressupostos psicanalíticos, sabemos que, para entrar na língua e na fala, é necessário separar a voz da língua. Isso só poderá acontecer se o objeto voz se conservar como inscrição significante no sujeito. Nesse sentido, a fala demanda que a voz seja esquecida. Assim, embora no autista a linguagem faça eco, não há o engano primordial. A criança autista não separa representação e coisa, ela se isola com seu objeto e coloca em operação um processo de substituição que admite induzir a coisa à linguagem (Maleval, 2012). Dessa forma, para dizer o mundo, a língua funcional de sinais consegue empregar os sinais sonoros ou da escritura vindos da língua do Outro.

Nesse contexto, a linguagem do autista permeia muito mais o Real de seu gozo que uma fantasia de comunicação Simbólico-Imaginária. Assim, os tropeços no movimento de tomada de posições diante da língua assinalam a fala do autista como rígida, remetendo-lhe uma impossibilidade de constituição da linguagem. Nesse sentido, com a holófrase do par primordial de significantes (S1-S2), a criança autista não faz uso da fala para estabelecer e colocar em funcionamento uma convenção social. Com efeito, a fala torna-se colada a um gozo sonoro 
impeditivo da geração do sentido estremado por seu alcance fálico para pôr em vigor o que da fala do Outro a abala.

Embora impossibilitados de elucubrar o ardiloso saber acerca de lalangue que baliza o discurso, os autistas apresentam um saber fazer com lalangue, caracterizado por sua dissociação da intenção de dizer algo. Sob esse prisma, na fala do autista, o uso do significante é apagado em relação ao signo e, de forma singular, essa fala não é centrada na comunicação, mas nem por esse motivo deixa de sinalizar um modo de gozo. Impera a relação do signo em detrimento do funcionamento do significante.

Diante disso, compreendemos que o autista pode se servir da fala por meio de quatro posições, quais sejam: a recusa radical da fala, a verbosidade, o uso de frases espontâneas e a língua factual. A recusa da fala é tomada como uma rejeição da dimensão enunciativa da voz, enquanto a verborragia, predicado da condição autista, "parece ter por função abafar e conter uma voz da qual ele receia a manifestação" (Maleval, 2007, p. 7). Já o uso de frases espontâneas ocorre em momentos de angústia. Elas escapam da condição de não falar do autista, não se endereçam ao Outro, pois se trata de uma enunciação atrelada ao seu próprio gozo. É uma fala isolada, acompanhada por outro longo silêncio. A língua factual, sem o engajamento da voz, comparece desprovida de singularidade, marcada por um tom monocórdico, monótono, sem afetação.

Nesses casos, o signo não apaga a coisa representada, portanto, não funciona como recipiente do gozo, por isso não serve para inscrever o gozo no corpo. Quando o autista faz uso da fala, exprime uma desconcertante indiferença com relação àqueles que se dirigem a ele. Nesse sentido, sua fala é incerta, seus termos incompreensíveis, caracterizando-se pela não consolidação do laço social sustido no gozo fálico. A posição do autista faz alusão ao reconhecimento da subjetividade em qualquer manifestação de existência humana, mesmo que esse modo de viver transgrida os modos, culturalmente instituídos, de estruturas subjetivas.

Assim, há no autismo uma língua privada, própria, "mais conectada à melodia que à significação" (Maleval, 2009, p. 249), isto é, à tarefa de comunicar. Com isso, em casos de autismo, a fala pode aparecer presa ao signo, afastada dos ruídos da língua e dos equívocos significantes, em uma relação direta com a coisa, fixada signo a signo. Com a apreensão dos signos, os autistas mantêm a coisa como o referente em uma relação de similaridade ou de continuidade.

Assim, a linguagem sígnica, sem cortes ou extração de gozo, opera como se o mecanismo de Ausstossung funcionasse de maneira direta, independentemente da Bejahung ou de certo direcionamento do afeto. Isso significa que, no primado do signo, a pulsão não é representada, prevalecendo a não vinculação entre a linguagem e a realidade emocional, lógica própria da rede significante. Sobre essa questão, importa destacar que:

Os signos são plurivalentes: sem dúvida representam alguma coisa para alguém; mas, desse alguém o status é incerto (...). Esse alguém, em última instância, pode ser o universo, uma vez que nele circula, dizem-nos, a informação. Todo centro em que ela se totaliza pode ser tomado por alguém, mas não por um sujeito. (Lacan, 1960/1998, p. 854)

Notamos, conforme o exposto, que Lacan diferencia signo de significante aceitando a acepção de signo de Pierce (noção de índice), ao tomar o signo como "aquilo que representa alguma coisa para alguém" (Lacan, 1960-61/1992, p. 232). Nessa operação, encontra-se o princípio do prazer, que faz o sujeito buscar, essencialmente, o "retorno de alguma coisa que é um signo" (Lacan, 1959-60/1997, p. 25). Nesses termos, a incidência de certa inércia da excitação pulsional sugere a compleição da Coisa. Em referência ao psiquismo, essa incidência labora como um signo. Logo, a "coisa que faz signo" (Lacan, 1959-60/1997, p. 85) é a manifestação de Das Ding, o resto constante e incompreensível de todo complexo perceptivo 
do sujeito. Ela é efeito da obra constituída a partir "disto que do interior do sujeito se encontra originalmente conduzido para um primeiro afora" (Lacan, 1959-60/1997, p. 87). Assim, ao se debruçar sobre o decurso do signo ao significante, Lacan pressupôs que:

o significante não consiste simplesmente em fazer signo para alguém, mas, no mesmo momento da mola significante, da instância significante, fazer signo de alguém - fazer com que o alguém para quem o sujeito designa alguma coisa, este signo o assimile, que o alguém se torne, ele também, este significante. (Lacan, 1960-1961/1992, p. 258)

Na lógica lacaniana, o significante, efeito de um corte duplo entre o significante e a coisa das Ding- e também entre os significantes, segmenta-se por cortes oriundos do próprio sistema, isto é, "cada um de seus elementos será, portanto, secção de corte" (Lacan, 1961-62 Inédito, p. 348). Ora, estruturalmente, o corte, entendido como pura diferença, emerge quando o traço (o corte primário, inscrição original) volta sobre si mesmo por meio de um recorte que permite a continuidade das superfícies, a passagem do interior para o exterior. Essa operação desdobra uma estrutura em outra. Dessa forma,

\begin{abstract}
o elusivo do corte que se recorta se expressa pelos termos "negatividade", "diferenças", que preexistem à unidade fictícia do signo. A unidade do signo encobre a existência da diferença enquanto tal, da qual procede, mas que não é em si mesma representável. (...) O corte cria Um, mas isso não se determina de antemão, e não conforma um código, ele se constitui como segmento de corte por outra segmentação, um S2 que Lacan, a partir de 1969, chama "saber". (Porge, 2014, pp.67-68 - grifo do autor)
\end{abstract}

Tendo em vista essa operação, vislumbramos que na fala dos autistas algo prescinde do significante e privilegia os signos, dando a eles sentido absoluto. Nesse caso, os signos conservam uma conexão de similaridade e de continuidade com a coisa que representa. Prevalece, assim, o isolamento de elementos linguísticos em relação à apreensão contextual. Os autismos, por esse ângulo, apontam uma questão extremamente instigante, pois geralmente se sentem ameaçados frente às variações da relação coisa/signo. Eles tendem resistir aos efeitos provocados pelo significante na linguagem. Maleval (2012) defende essa tese ao considerar que os autistas, em sua intenção de fala, amarram a palavra à imagem, detendo-se à existência de coisas. Para o autor, o primado do signo, enquanto distinto do significante, subjaz-se revelando outro modo de funcionar na estrutura da língua.

A partir da noção de linguagem, sob a ótica da psicanálise, sobretudo com Lacan, os autistas estão na linguagem desde seu nascimento. Embora eles tentem se proteger da linguagem, como no gesto de tapar os próprios ouvidos, são afetados pela inundação da fala. Assim, em alguns casos, na medida em que há a identificação mesmo de ausência/dificuldade de/na fala, os autistas se servem de algum modo da linguagem. Portanto, eles operam com a linguagem, não estão fora ou alheios a ela. Nessa relação, engendra-se algo do saber-fazer com a estrutura e com a alteridade, com o universal e com o particular, remetendo a tudo isso sua variante singular. Essa operação tem a ver com o modo como o autista se constitui na linguagem "para se sustentar no mundo como humano" (Burgarelli, 2000, p.75).

\title{
Considerações finais
}

Contrapondo-se aos manuais oficiais de diagnósticos e de estatísticas de transtornos mentais cuja tendência é diagnosticar e tratar o autismo como um transtorno, a psicanálise nos convoca, a partir de Freud e Lacan, ao reconhecimento da posição singular dos autistas em sua relação com a linguagem. Segundo os estudos psicanalíticos, diferentes da psiquiatria, as manifestações dos autistas são cingidas por uma opacidade que resiste a uma significação fixa. Essas 
manifestações não são tomadas a partir de um ideal de transcrição e categorização, nem por meio da tradução dos sintomas previamente construídos pela experiência clínica. Embora para a psicanálise a questão do autismo não se detenha apenas na função materna como estruturante do psiquismo, a relação de cuidado mãe-bebê

\begin{abstract}
nos força a distinguir entre a função social de cuidados que as mães podem desempenhar melhor ou pior e pela qual podem ser julgadas e uma função que em psicanálise chamamos de "função materna", que as mães desconhecem exercer, ou seja, realizam com o não-saber que marca o inconsciente. Ou seja, a função materna implica a estrutura psíquica inconsciente da mãe. E quanto a essa, não há como culpabilizar um sujeito; no entanto, a psicanálise não desresponsabiliza o sujeito quanto ao que o afeta e isto define uma posição do analista no trabalho de escuta junto aos pais, promovendo a responsabilização destes no sintoma do filho (Leite, 2005, p.292).
\end{abstract}

Essa perspectiva também é assumida pela psicanalista Colette Soler (1999). Com base na teoria lacaniana, Soler tomou o sintoma como enceto de singularidade e diferença, fundamental na dinâmica psíquica do sujeito. O sintoma é, assim, um modo de organização do gozo, possibilidade de haver unicidade. Ao contrário do discurso médico, reconhece-se que o sintoma emana do real - do corpo, das pulsões no dito freudiano - e interfere, contesta, objetando a conformidade do ser social. Este é produzido sob os efeitos culturais de uma civilização.

Diante do que foi discutido, sem a pretensão de tomar uma forma conclusiva, mas com o objetivo de manter aberta a questão sobre as modalidades de diferenciação entre autismos e psicoses, percebemos, a partir do trabalho clínico de Rosine e Robert Lefort, a possibilidade de se tomar o autismo como uma estrutura peculiar, independente da psicose, que inaugura uma nova possibilidade de posição estrutural para o sujeito. Essa compreensão abre caminhos para psicanalistas, como Vorcaro e Maleval, investigarem as especificidades dos autistas e sua relação com a linguagem, incluindo, nesse processo, o debate sobre novos e possíveis modos de tratamento clínico para autistas no campo psicanalítico.

Considerando o aporte conceitual de Vorcaro, o autismo foi tomado, para além das proposições psicopatológicas, como a maneira pela qual a criança se engendra no mundo da linguagem e como ela se posiciona na relação com o Outro. Para a psicanalista, nos autismos, algo incide no enodamento dos registros RSI e exclui o Imaginário da ligação com o Simbólico e o Real. Dito de outro modo, os autistas não praticam o imaginário via referência simbólica. Isso porque eles não efetuam a interpenetração entre o seu campo (do ser) e o do Outro.

Com isso, depreendemos que o enlaçamento no nó indica que os registros não se articulam por predominância ou por grau de estima ou mesmo de plano, visto que a escrita borromeana não suporta a primazia de um registro sobre outro. Tendo em vista essa elaboração, percebemos que as crianças autistas, embora entrem na alienação, apresentam dificuldades para realizar a intersecção entre os campos do ser e do Outro. Elas reconhecem o Outro em sua presença maciça, real, e não como uma presença simbólica. Nesse processo, o autista está aquém da articulação significante na substituição que o conduz entre significantes.

Na concepção de Maleval (2012), os autistas estão submetidos ao "primado do signo" e têm como premissa a formação de um código onde cada palavra tenha um significado só, fixo. Assim, diante do predomínio de referências imaginárias e da falta de acesso ao significante, os primeiros elementos da linguagem não são encadeados como relações de representação entre significantes, mas sim entre a coisa e a palavra, de forma biunívoca. Sob esse prisma, entendemos que a lógica singular põe em articulação as indeterminações psíquicas e o jogo pulsional. Importa reiterar que o singular no campo analítico é sustentado no fundamento de cada gesto, olhar, palavra etc., que se constitui em um caminho único e impossível de se repetir sem um ponto de diferença. 
À guisa de conclusão, cabe dizer que as interrogações sobre a estruturação subjetiva nos autismos reverberam a respeito do "não decidido" da estrutura no tempo da infância. Nesse sentido, a psicanálise toma a direção do tratamento dos autistas pelo reconhecimento do diferente como singular, em alteridade com o Outro que o constitui e não como expressão de anormalidade. Nessa perspectiva, cabe a ela então: "retificar e encontrar o sujeito, sua singular forma de estar no mundo e lidar com ele" (Vorcaro e Ferreira, 2017, pp.16-17). Assim, no enfrentamento dos paradoxos da estruturação subjetiva, em oposição ao estabelecimento de diagnósticos fechados, a intervenção psicanalítica na infância não constitui uma operação de prevenção, mas uma possibilidade de moderação do gozo.

\section{Referências}

Barthes, R. (1970). Crítica e verdade. São Paulo, SP: Perspectiva.

Burgarelli, C. G. (2000). Língua materna, autismo e estruturação do sujeito. Inter-Ação, 1(1), 69-77.

Dolto, F. (2002). Tudo é linguagem. São Paulo, SP: Martins Fontes.

Granon-Lafont, J. (1988). Atopologia de Jacques Lacan. Rio de Janeiro, RJ : Zahar.

Jerusalinsky, A. (1993). Psicose e autismo na infância: uma questão de linguagem. Boletim $A P P O A,(9), 62-73$.

Lacan, J. (1961[1962]). O seminário, livro 9: A identificação, 1961-1962. (AssociaçãoFreudiana Internacional, trad. provisória). (Seminário inédito).

Lacan, J. (1982). O seminário, livro 20: Mais, ainda, 1972-1973. (M. D. Magno, trad.). Rio de Janeiro, RJ: Zahar.

Lacan, J. (1984). A terceira. Opção Lacaniana, (62), 11-36. (Trabalho original de 1974).

Lacan, J. (1992). O seminário, livro 8: A transferência, 1960-1961. (D. D. Estrada, trad.). Rio de Janeiro: Zahar.

Lacan, J. (1997). O seminário. livro 7: A ética da psicanálise, 1959-1960. (A. Quinet, trad.). Rio de Janeiro, RJ: Zahar.

Lacan, J. (1998). Subversão do sujeito e dialética do desejo no inconsciente freudiano, In J. Lacan, Escritos (pp. 833-854). Rio de Janeiro, RJ: Zahar. Trabalho originlpublicado em 1960)

Lacan, J. (1961[1962]). O seminário, livro 9: A identificação, 1961-1962. (AssociaçãoFreudiana Internacional, trad. provisória). (Seminário inédito).

Lacan, J. (2005). O seminário, livro10: A angústia, 1962-1963. Rio de Janeiro, RJ: Zahar.

Lacan, J. (2010). O seminário, livro 2: O eu na teoria de Freud e na técnica da psicanálise, 1954-1955 (M. C. L. Penot, trad.). Rio de Janeiro, RJ: Zahar.

Lefort, R. \& Lefort, R. (1951-1952[1984]). O nascimento do Outro. Salvador, BA: Biblioteca Freudiana Brasileira.

Lefort, R. \& Lefort, R. (2017). A distinção do autismo. (A. L. Santiago \& C. Vidigal, trad.). Belo Horizonte, MG: Relicário.

Leite, N. V. A. (2005). Autismos: uma contribuição para se pensar o sujeito em psicanálise. Inter-Ação, 30(2), 289-296. 
Maleval, J. -C. (2007). Os objetos autísticos complexos são nocivos? Psicologia em Revista, $15(2), 223-254$.

Maleval, J. -C. (2009). L'autiste et savoix. Paris: Éditions Du Seuil.

Maleval, J. -C. (2012). Língua verbosa, língua factual e frases espontâneas nos autistas.In Murta, A. \& Calmon, A.; Rosa, M. (Org.), Autismo(s) e atualidade: uma Leitura lacaniana (pp. 49-50). Belo Horizonte, MG: Scriptum.

Maleval, J. -C. (2015). Por que a hipótese de uma estrutura autística? OpçãoLacaniana, $6(18), 1-40$.

Meira, A. M. B. (2020). Um modo de cifrar: autistas e a escrita de si. Dissertação de Mestrado em Psicologia, Universidade Federal de Minas Gerais, Belo Horizonte, MG.

Porge, E. \& Soulez, A. (1996). Le momentcartésien de lapsychanalyse:Lacan, Descartes, lesujetsousla dir. de Paris. Strasbourg: Arcanes.

Porge, E. (1998). Os nomes do pai em Jacques Lacan: problemáticas e pontuações. Rio de Janeiro, RJ: Companhia de Freud.

Porge, E. (2014). Fundamentos da clínica psicanalítica. (J. G. Milán-Ramos, trad.). Campinas, SP: Mercado de Letras. (Coleção Terramar)

Soler, C. (1999). Autismo e paranoia. In S. Alberto,. (Org.), Autismo e esquizofrenia na clínica da esquize (pp. 219-232). Rio de Janeiro, RJ: Marca d'Água.

Vorcaro, A. M. R. (1999). Transferência e interpretação na clínica com crianças autistas epsicóticas. Estilos da Clínica, 4(7), 52-72. doi: https://doi.org/10.11606/issn.19811624.v4i7p52-72

Vorcaro, A. M. R. (2004). A criança na clínica psicanalítica. Rio de Janeiro, RJ:Companhia de Freud.

Vorcaro, A. M. R. (2005). Crianças na psicanálise: clínica, instituição, laço social. Rio de Janeiro, RJ: Companhia de Freud.

Vorcaro, A. M. R. (2008). A angústia nos autismos e nas psicoses da infância. Reverso, 30(56), 27-34.

Vorcaro, A. M. R. (2017). Um refrão surdo ressoa no corpo. In Burgarelli, C. G. (Org.), Padecer do significante: a questão do sujeito (pp. 09-17). Campinas, SP: Mercado de Letras.

Vorcaro, A. M. \& Ferreira, T. (2017). O tratamento psicanalítico de criançasautistas: diálogo com múltiplas experiências. Belo Horizonte, MG: Autêntica.

Pozzato, V. G. \& Vorcaro, A. M. R. (2014). Aproximações e distinções entre os autismos e as psicoses em crianças: condições da alienação à linguagem. Analytica, 3(5),137-156.

Revisão gramatical: Varlene Rocha Brandão Bandeira

E-mail: bandeiravrb@gmail.com

Recebido em novembro de 2020 - Aceito em abril de 2021. 